no change in dimensions at end systole-so that the ejection fraction is decreased or little changed.

The origin of symptoms in these patients is less clear than in patients with acute heart failure. The classic teaching has been challenged by recent research. ${ }^{6-9}$ The feeling of breathlessness appears to be independent of changes in left atrial pressure as estimated from the pulmonary capillary wedge pressure. No correlation exists between the wedge pressure at rest or during maximal exercise and maximal oxygen consumption reached at the end of symptom limited exercise. ${ }^{79}$ The symptom which terminates exercise depends on the type of exercise performed despite the peak wedge pressure being the same. ${ }^{9}$ Rapid forms of exercise tend to result in breathlessness, whereas slower, prolonged forms of exercise come to an end because of fatigue. ${ }^{9}$ Furthermore, long term drug studies show that an improvement in exercise capacity is often but not invariably associated with an improvement in exercise haemodynamics and a fall in pulmonary capillary wedge pressure. ${ }^{10}$ Short term, vasodilator and inotropic agents almost always improve the haemodynamic indices and lower the pulmonary capillary wedge pressure but usually they do not increase exercise capacity either immediately or long term. ${ }^{11-13}$ In one study amrinone given acutely to patients with severe heart failure did increase exercise capacity and peak oxygen consumption-but the pulmonary capillary wedge pressure also increased, indicating that a high pulmonary capillary wedge pressure had not been the factor initially limiting exercise. ${ }^{14}$

The postulated link between a raised left atrial pressure and breathlessness in chronic heart failure is also weakened by the lack of any obvious physiological mechanism. Juxtapulmonary capillary receptors ("J" receptors) may be activated by stiffening of the lungs, as may occur with accumulation of interstitial fluid, and this causes tachypnoea and the feeling of breathlessness. ${ }^{15}$ Decreased lung compliance does not, however, correlate with the degree of dyspnoea ${ }^{16}{ }^{17}$ and patients with left ventricular dysfunction develop only small increases in pulmonary blood volume and pulmonary extravascular fluid. ${ }^{18}$

An alternative explanation relates to the many and complex metabolic changes during exercise. ${ }^{9}$ The blood flow through skeletal muscles is reduced in patients with heart failure. ${ }^{19}$ A metabolic acidosis develops during rapid forms of exercise, and this may stimulate peripheral chemoreceptors and contribute to the hyperventilatory response and the feeling of breathlessness.'

In patients limited by fatigue several studies have suggested that the cause is an inadequate oxygen supply to skeletal muscle. ${ }^{1920}$ During maximum exercise the oxygen content of blood in the femoral vein is negligible. ${ }^{21}$ Wilson $e t$ al showed that patients with chronic heart failure developed fatigue when the underperfusion of muscle reached a critical level and concluded that maximal exercise capacity of patients with heart failure was due to an impaired nutritive flow to the skeletal muscle. ${ }^{19}$ The mechanism may be an intracellular acidosis, accumulation of lactate, or depletion of phosphocreatinine. ${ }^{22}$ Persistent changes in the function of skeletal muscle also occur in chronic heart failure and may contribute to exercise limitation in these patients. ${ }^{23}$

What these research findings show, then, is that the limitation of exercise and the feelings of breathlessness or fatigue in patients with chronic heart failure have multifactorial mechanisms. Their symptoms should not be related solely to an altered haemodynamic response to exercise. Which symptom is limiting in an individual patient will depend on the different mechanisms influencing neural and metabolic signals from exercising muscle and the response of more central receptors.

D P LIPKIN

Research registrar

Philip A PoOle-Wilson

Professor of cardiology

Cardiothoracic Institute and National Heart Hospital,

London WIN 2DX

1 Franciosa JA, Park M, Levine TB. Lack of correlation between exercise capacity and indexes of resting left ventricular performance in heart failure. Am $\mathcal{F}$ Cardiol 1981;47:33-9.

2 Enger R, Ray R, Higgins CB, et al. Clinical assessment and follow up of functional capacity in patients with chronic congestive cardiomyopathy. Am J Cardiol 1982;49:1832-7.

3 Higgenbotham MB, Morris KG, Conn EH, Coleman RE, Cobb FR. Determinants of exercise performance among patients with severe left ventricular dysfunction. $A m \mathcal{F}$ Cardiol 1983;51: $52-60$.

4 Baker NJ, Wilen MM, Boyd CM, Dinh H, Franciosa JA. Relation of right ventricular ejection fraction to exercise capacity in chronic left ventricular failure. Am F Cardiol 1984;54:596-9.

5 Shen WF, Roubin GS, Hirasawa $\mathrm{K}$, et al. Left ventricular volume and ejection fraction response to exercise in chronic congestive heart failure: difference between dilated cardiomyopathy and previous myocardial infarction. Am f Cardiol 1985;55:1027-31.

6 Franciosa JA, Ziesche S, Wilen M. Functional capacity in patients with chronic left ventricular failure: relationship of bicycle exercise performance to clinical hemodynamic characterization. Am 7 Cardiol 1979;67:460-6.

7 Franciosa JA, Leddy CL, Wilen M, Schwartz DE. Relation between hemodynamic and ventilatory responses in determining exercise capacity in severe congestive heart failure. $A m \mathcal{F}$ Cardiol 1984;53:127-34.

8 Francis GS, Goldsmith SR, Cohn JN. Relationship of exercise capacity to resting left ventricular performance and basal plasma norepinephrine levels in patients with congestive heart failure Am Heart $\mathcal{F}$ 1982;104:725-31.

9 Lipkin DP, Poole-Wilson PA. Factors determining symptoms in chronic heart failure. Comparison of a fast and slow exercise test. $\mathrm{Br}$ Heart $\mathcal{J}$ (in press

10 Franciosa JA, Goldsmith SR, Cohn JN. Contrasting immediate and long term effects of isosorbide dinitrate on exercise capacity in congestive heart failure. Am J Cardiol 1980;69:559-66.

11 Packer $M$. Conceptual dilemmas in the classification of vasodilator drugs for severe heart failure. Am F Med 1984;76:3-13.

12 Franciosa JA, Dunkman B, Leddy CL. Hemodynamic effect of vasodilators and long term response in heart failure. Fournal of the American College of Cardiology 1984;3:1521-30.

13 Lipkin DP, Poole-Wilson PA. Treatment for chronic heart failure: a review of recent drug trials. BrMed f 1985;291:993-6.

14 Siskind SJ. Sonnenblick EH, Forman R, Schever J, LeJemtel TH. Acute substantial benefit of inotropic therapy with amrinone on exercise hemodynamics and metabolism in severe congestive heart failure. Circulation 1981;64:966-73.

15 Pantol AS. Mechanisms of stimulation of type J pulmonary receptors. $\mathcal{F}$ Physiol 1969;203:51 1-32. 6 Frank RN, Cugell DW, Caensler EA, Ellis LB. Ventilatory studies in mitral stenosis. Am $\mathcal{J}$ Med 1953:15:60-75

17 Haywood GW, Knott JMS. The effect of exercise on lung distensibility and respiratory work in mitral stenosis. Br Heart f 1955; 17:303-11.

18 Austin SM, Schreiner BF, Shah PM, Yu PN. Acute effects of increased pulmonary vascular distending pressure on pulmonary blood volume and pulmonary extravascular fluid volume in man. Circulation 1976;53:356-63.

19 Wilson JR, Martin JL, Schwartz D, Ferraro N. Exercise intolerance in patients with CHF: role of impaired nutritive flow to skeletal muscle. Circulation 1984;69:1079-87.

20 Donald $\mathrm{KW}$, Wormold PN, Taylor SH, Bishop JM. Changes in the oxygen content of femoral venous blood and leg based flow during leg exercise in relation to the cardiac output response.

21 Canepa-Anson R, Poole-Wilson PA. Vasodilator therapy in left ventricular failure. Effect of prazosin on the distribution of blood flow. Br $\mathcal{A}$ Clin Pract 1984; suppl 29:30-3.

22 Wilson JR, Fink L, Mario J, et al. Evaluation of energy metabolism in skeletal muscle of patients with heart failure with gated phosphorus-31 nuclear magnetic resonance. Circulation 1985;71:

23 Lipkin DP, Jones DA, Round J, Poole-Wilson PA. Maximal force, type and enzymatic activity in quadriceps of patients with severe heart failure; a mechanism for reduced exercise capacity. $\mathrm{Br}$ Heart 7 1985;54:622A

\section{The Nuffield report: a signpost for pharmacy}

Two years ago we reported the setting up of the Nuffield Foundation Pharmacy Inquiry and discussed some of the problems facing our pharmaceutical colleagues in the various branches of their profession. ${ }^{1}$ The report of the committee of inquiry, on which there were three medical members, has now been published and, as we forecast, its conclusions and recommendations are far reaching. ${ }^{2}$ The face of pharmacy will change appreciably over the next decade if they are put into effect, and they will have an impact on other health professions, including medicine.

The general tone of the report is positive and optimistic, 
reflecting the view expressed by the committee's chairman, Sir Kenneth Clucas: "the pharmacy profession has a distinctive and indispensable contribution to make to health care that is capable of still further development." It is with this "further development" that the report is concerned.

The largest part of the report deals with community pharmacy, often known as general practice pharmacy. Their education and training equip pharmacists to play a "unique and vital role" in provision of health care in the community, but this is not being realised in practice. They spend ever less time personally dispensing prescriptions, and with the increasing introduction of computers into general practitioners' surgeries as well as into pharmacies their valuable function as "long stops" to refer back faulty scripts to the prescriber will also decrease. The report recommends that pharmacists and general medical practitioners should cooperate on a systematic basis to increase the effectiveness and reduce the costs of prescribing. This cooperation should include regular discussions on appropriate medication, drug interactions, and adverse drug effects. This recommendation has already received the support in principle of the Pharmaceutical Society of Great Britain, the British Medical Association, and the Royal College of General Practitioners. A more controversial recommendation is that a pilot study should be set up to explore the usefulness of adverse drug reaction reporting by community pharmacists. A recent report of the Adverse Reactions Working Party of the Committee on Safety of Medicines did not support this proposal, however, though Professor David Grahame-Smith, its chairman, was a member of the Nuffield Inquiry Committee. ${ }^{3}$ There is no valid reason why undesirable clinical events possibly associated with drug treatment should not be reported by pharmacists, who may well see the patient much earlier than does the doctor, and this recommendation should be implemented as soon as possible.

\section{Advice from pharmacists}

The report takes a cautious approach to the possible contribution of the community pharmacist in giving advice on symptoms. While welcoming the willingness of pharmacists to offer much advice, it emphasises the importance of proper education and training to perform that task, which must include the ability to decide when the inquirer should be recommended to seek medical advice. It is warmer, however, in its recommendations that pharmacists should give advice on taking medicines and on the use of devices, and that this advice should be concentrated on those groups who will most benefit from it, particularly the elderly. In fact it goes so far as to recommend that the elderly should be encouraged to register with a single pharmacy in which their medication records would be kept. The chronic sick and mentally handicapped are also specifically mentioned as being candidates for additional support and help from the pharmacist. His role should extend into the patient's home, the report suggests, not only for the domiciliary oxygen service, but also for help in providing and administering complex drug regimens, parenteral nutrition, and with patients with particular problems such as the seriously disabled or blind.

The report does not gloss over the fundamental problem of remuneration of the community pharmacist and its influence on his work. There is, it recognises, "a clash between the promotion of what is professional and the requirements of running a business." This obviously has implications for the giving of advice already referred to, when a medicine may not be required and so no fee is forthcoming. The recruitment of pharmacists to health centres has also been affected by thiso conflict. It had been hoped that such centres would have provided good opportunities for doctors and pharmacists tक work closely together, but this has generally not come about. This, says the report, is because the establishment of ap pharmacy in a health centre does not represent new business but redistribution of business previously conducted by existing pharmacies in the centre's catchment area. The pharmacy in the centre is usually run by a consortium of existing pharmacy owners, who have to offset the loss of business in their own pharmacies by processing and dispens-듬 ing the prescriptions at least cost. The report concludes? unhappily that "as a result the service provided in some health centre pharmacies is worse than can be foundes elsewhere."

\section{New pattern of payments}

In order to remove, at least in part, this conflict between professional and commercial interests the report recomos mends that the basis of remuneration of community pharma cists should be changed so that the objectives set for theprofession may be reinforced. In particular it suggests thate payments under the NHS contract in respect of prescrip-o tions dispensed should be reduced and separate payments made for other professional activities such as work done in collaboration with doctors, advice to patients, long termp patient care, domiciliary activities, and health education.

Turning to clinical pharmacy the report rightly emphasise the importance of maintaining a flexible definition of its function in the context of local requirements in a particularo hospital setting. ${ }^{4}$ It recommends, however, that clinicas pharmacy should be practised in all hospitals, the clinica $\overline{\bar{P}}$ pharmacist being concerned in providing the clinician with information and advice on drug medication, in therapeutic drug monitoring, in reporting adverse drug reactions, and ine clinical trials. To release more highly trained staff on to the wards for these functions and to "maximise scarce resources,' all activities within the hospital pharmacy should be carried out by staff at the most junior level competent to perform it This will often mean pharmacy technicians rather than graduate pharmacists. Clinical pharmacists should be ap pointed, together with doctors and nurses, to drug ands therapeutics committees. Specialisation within clinical phar-3 macy should increase not only in the recognised functions of production, quality control, radiopharmacy, and drug in-n formation, but also in large individual clinical departments such as oncology, paediatrics, and psychiatry. Pharmacists in drug information, the report recommends, should remain in touch with work at ward level because "the provision of w evaluated information requires in those giving it a recognitiono of the clinical context within which the information is to be used." There is more to the provision of drug information than the development of more complex databases, and the $e^{+}$ educational requirements of pharmacists aspiring to carry out this function need consideration not given in the report $\frac{\vec{\Phi}}{\mathrm{D}}$ Finally, the report recognises the difficulties that have arisen between medical and pharmacy staff within some hospitals because of misunderstanding about the nature of clinicak pharmacy and welcomes the increasing cooperation betweeng pharmacists and junior hospital doctors. This should lead in the future not only to better relations within hospitals, bue also to closer cooperation between those doctors who become 
general practitioners and their neighbouring community pharmacists.

More pharmacists should be recruited into the pharmaceutical industry, the report recommends, not only because of the breadth of their training but because their membership of a professional body (Pharmaceutical Society of Great Britain) "imposes a duty on them to maintain standards which can be of great assistance to the firm that employs them." The report mentions advertising and marketing of products as particular aspects of their work where such standards would be important.

The developments in the practice of pharmacy recommended in the report can take place only if there are radical changes in undergraduate and postgraduate education. While the undergraduate course should continue to be strongly science based, the report recommends, science must be relevant to the practice of pharmacy today and not be constrained by the traditional organisation of the subject into pharmaceutics, pharmaceutical chemistry, and pharmacology. Time must be found in the course for increased teaching of those aspects of pathology, therapeutics, and social and behavioural sciences which are relevant to the students' future professional tasks. There seems to be an anomaly in the report on the question of provision within the undergraduate course for contact with the public, patients, and doctors. Though it appears to recognise that students in most schools (Bradford University alone incorporates two six month periods of practical experience within a four year sandwich course) have little or no contact with the "real world of pharmacy," that many teachers are not pharmacists, and that there is widespread concern that learning and practice are insufficiently integrated, it does not recommend that the course should be increased to four years in all schools in order to provide time for practical experience and contact with patient and public. This is a pity, for pharmacy is the only registrable health professional qualification that does not include such experience in its undergraduate course, and young graduate pharmacists may experience great difficulty in communicating with the public and with colleagues in other professions in their preregistration year.

\section{Test of competence}

A controversial recommendation which perhaps follows from this is that there should be a test of competence at the end of the preregistration year, whose emphasis should be on practical work and oral skills, and that this should be followed by further "continuing assessment of practice, the ability to pass which should, in due course be made a condition of continued registration." This has already attracted criticism from at least one pharmacist, who points out that other members of the "health team" such as nurses, dentists, and doctors are not subjected to "such blatant lack of confidence."' The Pharmaceutical Society of Great Britain should rethink its policy on undergraduate practical experience which could, as Bradford University has already shown, be accommodated in a four year course acceptable for registration.

The responsibility for most of the recommendations made in the report will rest on the Pharmaceutical Society of Great Britain, and this is recognised by the committee of inquiry, which has drawn attention to the need for the society to define more clearly-and then to enforce-standards of acceptable conduct in community pharmacy.
The Nuffield report points the way forward to our pharmaceutical colleagues, but medicine cannot avoid being caught up in the wake of the resulting changes. As drugs become more complex in their actions and interactions so prescribing doctors will become increasingly dependent on colleagues in clinical pharmacology and pharmacy to advise on their best use, and because departments of clinical pharmacology are all too few and far between pharmacists will be the source of such advice for most hospital doctors and general practitioners. Finally, it is inconceivable that continuing assessment of practice could be adopted by one health profession without demands for it to be mandatory on all, and our own colleges and representative bodies will be watching closely to see how pharmacy responds to this recommendation.

Professor of Clinical Pharmacology,

PAul Turner

St Bartholomew's Hospital,

London EC1A 7BE

Turner P. Pharmacy: an inquiry into its contribution to patient care. Br Med f 1984;288:810-11. 2 Committee of Inquiry. Pharmacy. A report to the Nuffeld Foundation. London: Nuffield Foundation, 1986.

Committee on Safety of Medicines. Report of the Adverse Reactions Working Party. London: Department of Health and Social Security, 1985.

4 Turner P. Clinical pharmacy and clinical pharmacology. Pharmaceutical fournal 1985;235:577.

5 Shetewi B. Nuffield report. Pharmaceutical fourmal 1986;236:383.

\section{Treatment of type II diabetes}

The logical treatment of type II non-insulin-dependent diabetes is hampered by our lack of knowledge of its aetiology and pathogenesis.

Recent evidence suggests that some insulin deficiency coexists with insulin resistance. ${ }^{12}$ The interplay between the two defects - or whether one is primary-remains unclear. These uncertainties make for difficulties in assessing the mechanism and appropriateness of standard treatments, and as a result the approach is largely pragmatic. Treatment seems simple: dietary manipulation and if this fails oral hypoglycaemic agents ${ }^{3}$; and some patients eventually become treated with insulin but are not, by current classification, ${ }^{4}$ insulin dependent.

In recent years this line of treatment has been subject to variation with changes in evidence and fashion. In 1970 publication of the University Group Diabetes Program study of tolbutamide and phenformin showing increased cardiovascular mortality with both drugs led in the United States but not in Europe to a dramatic move away from the use of oral hypoglycaemic agents. ${ }^{5}$ The refutation and repudiation of these findings only partly reversed this trend. ${ }^{6}$ The long term results of the British prospective study of treatment in maturity onset diabetes should clarify this issue. In the mean time large centres treating diabetic patients can point to many examples of people spared treatment with insulin by the judicious use of oral agents.

Years of clinical use have not clarified the mechanism of action of sulphonylureas. At first their administration raises the concentration of insulin in the blood, but in the long term this is not the means to a hypoglycaemic effect. Eventually the blood glucose concentration is reduced despite the insulin concentrations returning to pretreatment levels. ${ }^{78}$ This finding has led us to the concept of an extrapancreatic mechanism of action. The data are compatible with an enhancement of the secretion of insulin in response to 